\title{
Desinfección de segmentos nodales en el establecimiento in vitro de Erythrina americana Miller.
}

Disinfection of nodal segments in the in vital establishment of Erythrina americana Miller.

\author{
Martínez Hernández María de Jesús ${ }^{1}$, Sánchez Hernández Sandra Ivonne ${ }^{1}$, Castillo Rocha \\ Doris $^{1}$, Rodríguez Mauricio Luna. ${ }^{2}$ \\ ${ }^{1}$ Facultad de Ciencias Agrícolas Campus Xalapa, Universidad Veracruzana. Circuito \\ Gonzalo Aguirre Beltran S/N. C.P. 91090 Xalapa, Veracruz.
}

${ }^{2}$ LATEX, Laboratorio de Alta Tecnología Xalapa, Calle Médicos No. 5 Col. Unidad del Bosque Xalapa, Veracruz C.P. 91010. Universidad Veracruzana

${ }^{凶}$ Autor de correspondencia mhernandezmj@ gmail.com

Recibido: 18/02/2017

Aceptado: 30/06/2017

\section{RESUMEN}

Con la finalidad de establecer un protocolo de desinfección y multiplicación in vitro para la obtención de plántulas de Erythrina americana Miller, se evaluaron dos diferentes desinfectantes etanol e hipoclorito de sodio en concentraciones porcentuales de 35, 45, 55, 65 y 70 (v/v) y 20, 25, 30, 35 y 40 respectivamente, con tiempos de inmersión de 5, 10, 15, 20 y 25 minutos para ambos; se utilizaron segmentos nodales de $2.0 \mathrm{~cm}$ de longitud. El medio de cultivo utilizado fue Murashige y Skoog (MS) adicionado con 3\% de sacarosa, vitaminas y bencilamino purina (BAP) $0.5 \mathrm{mgL}^{-1}$ y Ácido indolbutírico (AIB) $0.1 \mathrm{mgL}^{-1}$. Los resultados mostraron que la inmersión de los segmentos nodales en elevadas concentraciones y tiempos prolongados registraron el $100 \%$ de muerte por necrosis de los tejidos, sin embargo, con las soluciones de etanol al $35 \%(\mathrm{v} / \mathrm{v})$ e hipoclorito de sodio al 30\% (v/v) con un tiempo de cinco minutos de inmersión, controlaron la contaminación fúngica o bacteriana, sin afectar la viabilidad de los segmentos nodales. Con la concentración de BAP $0.5 \mathrm{mgL}^{-1}$ y AIB $0.1 \mathrm{mgL}^{-}$ 1 , se estimuló una yema durante la etapa de multiplicación, lo cual indicó, que es necesario hacer más combinaciones de reguladores del crecimiento a fin de obtener la concentración óptima que estimulen el mayor número de yemas posibles. Los resultados obtenidos permitieron comprobar que micropropagar esta especie es una alternativa viable para su comercialización, conservación y reforestación de zonas degradas.

Palabras clave: in vitro, segmentos nodales, micropropagación.

\begin{abstract}
In order to establish an in vitro multiplication and disinfection protocol for the production of American Erythrina Miller seedlings, two different disinfectants ethanol and sodium hypochlorite were evaluated in percentage concentrations of 35, 45, 55, 65 and $70(\mathrm{v} / \mathrm{v})$ and 20, 25, 30, 35 and 40 respectively, with an immersion time of 5, 10, 15, 20 and 25 minutes for both; $2.0 \mathrm{~cm}$ long nodal segments were used. The culture medium used was Murashige and Skoog (MS) added with 3\% sucrose, vitamins and BAP $0.5 \mathrm{mgL}-1$ and AIB $0.1 \mathrm{mgL}-1$, a yolk was stimulated during the multiplication stage, which indicates that it is necessary to make more combinations of growth regulators in order to obtain the optimum concentration that stimulate the greatest number of possible buds. The results obtained showed that


micropropagation of this species is a viable alternative for the commercialization, conservation and reforestation of degraded areas.

Key words: in vitro, nodal segments, micropropagation

\section{INTRODUCCIÓN}

El árbol de Erythrina americana es de la familia Fabáceae, el nombre alude al color prevaleciente de las flores y deriva del griego erythros = rojo; comprende 115 especies distribuidas a través de las regiones tropicales del mundo; 25 de ellas se encuentran en México. (García-Mateo, et al., 2001). En especial la especie Erythrina americana Miller que en el siglo XVII, el Códice Florentino le atribuye únicamente valor estético. En el mismo siglo Francisco Hernández comentó: "el jugo exprimido e instilado en la boca de los infantes les produce sueño". Hasta el siglo XX se vuelve a registrar más información sobre esta planta. En México las flores se ha reportado el uso etnomédico como antídoto, antiinflamatorio, narcótico, contra dermatosis que producía parálisis (Brito, 2005). Se encuentra en todo el trópico y subtrópico de México, en los estados de México, Puebla, Tabasco, Veracruz, Chiapas y Yucatán. En Tlaxcala se le localiza como cerca viva en huertos familiares, traspatios y jardines públicos del centro y sur del estado. La especie $E$. coralloides crece en de clima frío o templado y $E$. americana crece en regiones más cálidas. (García-Mateo, et al., 2001). En el estado de Veracruz la especie de $E$. americana Miller se puede encontrar en algunos linderos y en algunos patios de los municipios de Acajete, Banderilla, Emiliano Zapata y Rafael Lucio. En los estudios realizados hasta ahora, no se encuentran plantaciones, ni datos de que mencionen que se está conservando esta especie, el poco interés de los pobladores de recolectar y sembrar las semillas ha originado que cada vez excitan menos árboles. Un método alterno es la propagación in vitro el cual es el conjunto de técnicas usadas para crecer células, tejidos u órganos vegetales, se cultiva bajo condiciones asépticamente en un medio artificial de composición química definida y se incuba en condiciones ambientales controladas (Pérez-Molphe-Balch et al., 1999) es importante, ya que permite obtener un gran cantidad de plantas en menor tiempo y espacio. El objetivo de este trabajo, fue establecer un protocolo de desinfección y multiplicación in vitro para la obtención de plántulas de Erythrina americana Miller.

\section{MATERIALES Y MÉTODOS}

El medio de cultivo utilizado para toda la investigación fue Murashige y Skoog (MS) (Murashige y Skoog 1962) y agar (Sigma (®) $6 \mathrm{~g} \mathrm{~L} \mathrm{~L}^{-1}$ y $30 \mathrm{gL}^{-1}$ de Sacarosa, adicionándole en la etapa de multiplicación BAP $1 \mathrm{mg} \mathrm{L}^{-1}$. suplementándolo con AIB $0.1 \mathrm{mgL}^{-1}$ y vitaminas (Myo-inositol 0.1 $\mathrm{mg} \mathrm{l}^{-1}$, Thiamine $0.1 \mathrm{mg} \mathrm{l}^{-1}$ y Pyridoxine $0.5 \mathrm{mg} \mathrm{l}^{-1}$ ). Se ajustó el $\mathrm{pH}$ a $5.8 \mathrm{con} \mathrm{KOH}$ $1 \mathrm{~N}$ o $\mathrm{HCl} 1 \mathrm{~N}$ antes de adicionar el agar; se esterilizó en la autoclave a $120^{\circ} \mathrm{C}$ durante 20 minutos. Colocándose $20 \mathrm{~mL}$ del medio de cultivo en un frasco de vidrio, previamente esterilizado, de una capacidad de $120 \mathrm{~mL}$.

Los explantes (segmentos nodales) fueron obtenidos de brotes de plantas madres, ubicadas en intemperie en el rancho denominado "María", que se encuentra ubicado en Piletas Veracruz. Las varetas fueron tomadas de los primeros $15 \mathrm{~cm}$ superiores de los brotes. Al momento de la colecta de ellos, fueron colocados en papel periódico húmedo y en una hielera a fin de que no se deshidrataran. En el laboratorio se procedió a quitar las hojas y la desinfección del material vegetal (varetas) fue de manera superficial, se lavaron por dos ocasiones con agua potable, jabón líquido y un cepillo 
de cerdas suaves para eliminar sedimentos y segmentos nodales de $2.0 \mathrm{~cm}$ de longitud. Además se adicionaron dos gotas de Tween 80 por cada $100 \mathrm{~mL}$ de solución, durante 15 minutos. Posterior a esto se realizaron los tratamientos (Tabla1). Dentro de la cámara de flujo laminar se realizaron tres enjuagues con agua destilada estéril, para cada uno de los tratamientos. partículas grandes. Se cortaron en En cada frasco se colocaron 3 segmentos nodales para su brotación, se cultivaron a una temperatura de $25^{\circ} \mathrm{C}$ y un fotoperiodo de $16 \mathrm{~h}$ luz y $8 \mathrm{~h}$ de oscuridad. El diseño experimental fue completamente al azar, la unidad experimental la constituyeron 16 frascos que contenían 3 brotes cada uno. Repitiéndose este experimento cuatro veces.

Tabla 1. Tratamientos concentración y tiempos de exposición

\begin{tabular}{|c|c|c|c|c|c|}
\hline Tratamientos & $\begin{array}{l}\text { Etanol \% } \\
(\mathrm{v} / \mathrm{v})\end{array}$ & $\begin{array}{l}\text { Tiempo } \\
\text { (minutos) }\end{array}$ & Tratamientos & $\begin{array}{l}\text { Hipoclorito de sodio } \\
\qquad \%(v / v)\end{array}$ & $\begin{array}{l}\text { Tiempo } \\
\text { (minutos) }\end{array}$ \\
\hline 1 & 35 & 5 & 1 & 20 & 5 \\
\hline 2 & 35 & 5 & 2 & 25 & 5 \\
\hline 3 & 35 & 5 & 3 & 30 & 5 \\
\hline 4 & 35 & 5 & 4 & 35 & 5 \\
\hline 5 & 35 & 5 & 5 & 40 & 5 \\
\hline 6 & 45 & 10 & 6 & 20 & 10 \\
\hline 7 & 45 & 10 & 7 & 25 & 10 \\
\hline 8 & 45 & 10 & 8 & 30 & 10 \\
\hline 9 & 45 & 10 & 9 & 35 & 10 \\
\hline 10 & 45 & 10 & 10 & 40 & 10 \\
\hline 11 & 55 & 15 & 11 & 20 & 15 \\
\hline 12 & 55 & 15 & 12 & 25 & 15 \\
\hline 13 & 55 & 15 & 13 & 30 & 15 \\
\hline 14 & 55 & 15 & 14 & 35 & 15 \\
\hline 15 & 55 & 15 & 15 & 40 & 15 \\
\hline 16 & 65 & 20 & 16 & 20 & 20 \\
\hline 17 & 65 & 20 & 17 & 25 & 20 \\
\hline 18 & 65 & 20 & 18 & 30 & 20 \\
\hline 19 & 65 & 20 & 19 & 35 & 20 \\
\hline 20 & 65 & 20 & 20 & 40 & 20 \\
\hline 21 & 70 & 25 & 21 & 20 & 25 \\
\hline 22 & 70 & 25 & 22 & 25 & 25 \\
\hline 23 & 70 & 25 & 23 & 30 & 25 \\
\hline 24 & 70 & 25 & 24 & 35 & 25 \\
\hline 25 & 70 & 25 & 25 & 40 & 25 \\
\hline
\end{tabular}

Los datos obtenidos se analizaron estadísticamente mediante el programa SAS (SAS Institute, Inc. 1997. Se realizó el análisis de varianza y comparación de medias de Tukey $(\mathrm{p}<0.05)$. 


\section{RESULTADOS Y DISCUSIÓN}

Desinfección de segmentos nodales.

En la figura 1, se puede observar que no hubo diferencias estadísticas entre tratamientos para la supervivencia de segmentos nodales, el tratamiento 1 , que fue las soluciones de etanol al $35 \%$ (v/v) e hipoclorito de sodio al $30 \%(\mathrm{v} / \mathrm{v})$ con un tiempo de cinco minutos de inmersión obtuvo el $100 \%$, mientras que en los demás tratamientos la respuesta fue nula, se pudo observar la muerte de los tejidos por necrosis, esto afecto severamente la supervivencia de los explantes. Alvarado 1998, ha reportado este efecto en otras especies, dado que el empleo de dosis elevadas de agentes desinfectantes elimina la microbiota contaminante pero causa la muerte de todos los explantes utilizados.

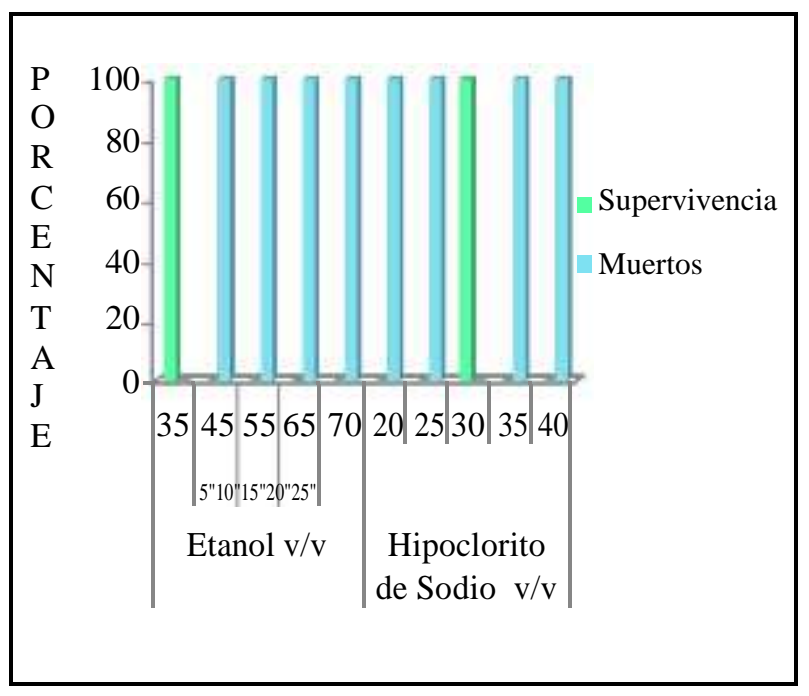

Figura 1. Porcentaje de supervivencia de segmentos nodales

Asimismo Uribe et al., 2008, menciona que en Berberidopsis corallina, (michay rojo) durante la etapa de establecimiento, el factor limitante en la supervivencia y viabilidad de los explantos es el tratamiento de desinfección aplicado. De acuerdo a Cassells (1991), los contaminantes en el cultivo de tejidos pueden causar grandes pérdidas en los procesos de propagación in vitro. Según Abdelwahd et al.,(2008) y Pedroza et al.,(2007), la obtención de explantes para iniciar actividades de cultivo in vitro, necesariamente implica causar cortes o heridas en los tejidos, los cuales facilitan la entrada de nutrientes y fitohormonas, pero favorecen también la exudación de compuestos relacionados con la cicatrización y defensa contra agentes externos (principalmente patógenos), estos compuestos generalmente de estructura fenólica, son rápidamente oxidados, causando el oscurecimiento del medio de cultivo y de los tejidos, haciendo que estos se necrosen y mueran. De ahí la importancia de su eliminación desde la fase de establecimiento, donde los daños son menores debido al menor volumen de explantes que se manipulan. Es importante mencionar que las altas concentraciones

controlan la aparición de hongos y bacterias, sin embargo los explantes mueren, esto coincide con lo mencionado por Folgueras et al. (2001); Das y Pal (2005); Rodríguez et al, (2008), que indican que los contaminantes más comunes durante el establecimiento in vitro de explantes procedentes de plantas adultas son los hongos y las bacterias que habitan de manera normal en el cultivo de las

mismas en condiciones naturales. Alternamente se ha realizado la desinfección de yemas axilares de diferentes especies de bambú, con una combinación de fungicidas y bactericidas y posterior sumergimiento de los explantes en hipoclorito de sodio al $1.5 \%$ durante 10 minutos (Jiménez et al., 2006). Igualmente se ha realizado la desinfección de los segmentos nodales con hipoclorito de sodio al $1 \%$ durante 5 minutos (Freire et al., 2011). Lo antes mencionado y los resultados obtenidos coinciden con lo mencionado por Alves Dos Santos et al. (2010), una desinfección eficaz es aquella en la que los explantes que han sido expuestos a una baja concentración desinfectante, presentan tasas reducidas de contaminación microbiana y oxidación. 
En la multiplicación cuando se le adicionó al medio de cultivo MS la concentración de BAP $0.5 \mathrm{mgL}^{-1}$ y AIB $0.1 \mathrm{mgL}^{-1}$, estimuló una yema, lo cual indicó que la concentración por debajo de $1 \mathrm{mgL}^{-1}$ de BAP no fue suficiente para la brotación de las yemas independientemente de la concentración de AIB. Resultados semejantes fueron obtenidos por Fick (2007), que partiendo de segmentos nodales de propágulos seminales germinados in vitro, evaluó distintas concentraciones de BAP combinado con ANA, concluyó que la adición de reguladores de crecimiento ya sea individual o combinada no promovió mejores resultados respecto al tratamiento sin hormonas. Por otro lado, Montavani et al. (2001), partiendo de segmento nodales (Cordia trichotoma) de seis meses de edad, obtuvo una mayor elongación y multiplicación de los brotes con BAP y GA3 (Ácido giberelico). Schendelbek (2007) concluyó que para la fase de multiplicación de brotes de Peteribí, los mejores resultados en cuanto al número de brotes por explante y coeficiente de multiplicación se obtuvieron con el empleo de $1.0 \mathrm{mgL}^{-1}$ de BAP con o sin la adición de $0.1 \mathrm{mgL}^{-1}$ ANA incluso de otro regulador.

\section{CONCLUSIONES}

La desinfección de las plantas madres es indispensable para disminuir la contaminación en la fase de establecimiento del material vegetal.

La inmersión de los segmentos nodales en etanol 35\% (v/v) durante cinco minutos y luego en solución de hipoclorito de sodio al $30 \%$ (v/v) durante cinco minutos, logró un control de la contaminación y no afectó la viabilidad del segmento nodal, mientras que a concentraciones altas de etanol e hipoclorito de sodio y tiempos de exposición prolongados causa la muerte de los tejidos por necrosis de los mismos. El uso de hormonas BAP y AIB no promovió una mayor brotación de los explantes. Los resultados obtenidos permitieron comprobar que micropropagar esta especie es una alternativa viable para su comercialización, conservación y reforestación de zonas degradas.

\section{AGRADECIMIENTOS}

A las Plataformas de Innovación Tecnológicas de la Facultad de Ciencias Agrícolas Campus Xalapa, Universidad Veracruzana y al Proyecto "Diagnostico, propagación y alternativas de conservación para la especie Erythrina americana Miller, en el municipio de Actopan, Veracruz. SUPRO:PIT-PE007"

\section{LITERATURA CITADA}

Abdelwahd, R., Hakam, N., Labhilili, M., \& Udupa, S. M. 2008. Use of an adsorbent and antioxidants to reduce the effects of leached phenolics in in vitro plantlet regeneration of faba bean. African Journal of Biotecnology, 7(8), 997-1002.

Alvarado Y. 1998. Contaminación microbiana en el cultivo in vitro de plantas. In Pérez JN ed. Propagación y mejora genética de plantas por biotecnología. Instituto de Biotecnología de las Plantas, Cuba. p. 81-104

Alves Dos Santos, M. R., Rodrigues Ferreira, M. D. G., De Oliveira Correia, A., \& Félix Da Rocha, J. 2010. In vitro establishment and callogenesis in shoot tips of Peach Palm. Revista Caatinga, 23(1), 40-44.

Brito. F. I.C. 2005. Zompantle o colorín (Erythrina americana Miller). Edición electrónica. Revista Tlahui-medic No. 20. México

Cassells AC. 1991. Problems in tissue culture: culture contamination. In debergh P, RH Zimmerman eds. Micropropagation. Dordrecht, The Netherland. Kluwer Acad. Publish. p. 31-45. https://doi.org/10.1007/978-94-009-2075-0_

Das, M.; Pal, A. 2005. In vitro regeneration of Bambusa balcoa Roxb. Factors affecting changes of morphogenetic competence in 
axillary buds. Plan Cell Tissue and Organ Culture 81 (1):109-112.

https://doi.org/10.1007/s1 1240-004-3017-x

Freire M, García Y, Hurtado O, León M, Fajardo L, Cruz M, Sánchez C, Alvarado Y, Acosta M, Tejada M, Roque B, Leiva M.

2011. Combinación de técnicas biotecnológicas y tradicionales para la propagación de diferentes especies de bambú. Biotecnología vegetal Vol. 11, $\mathrm{N}^{\mathrm{o}}$ 3:163 -168. Cuba.

Folgueras, M., Herrera, L., Carrazana, D. 2001. La contaminación microbiana en la micropropagación in vitro de las raíces y tubérculos tropicales. En: Libro de reportes cortos.Ciego de Ávila: Taller internacional BioVeg'2001,pp.183-185.

García-Mateos, R., Soto-Hernández., Vibrans, H. 2001. Erytrina americana MILLER ("Colorín"; Fabácea), a Versátil Resource from México: a Review. Economic Botany 55(3):391-400

https://doi.org/10.1007/BF02866562

Jiménez V, Castillo J, Tavares E, Guevara $\mathrm{E}$, Montie M. 2006. In vitro propagation of the neotropical giant bamboo, Guadua angustifolia Kunth, through axillary shoot proliferation. Plant cell tiss. Org. Cult. 86: 389 - 395.

https://doi.org/10.1007/s11240-006-9120-4

Mantovani; N. C.; Franco E. T.; Henz, Vestena S. 2001. Regeração in vitro de Louro-Pardo (Cordia trichotoma. (Vell.) Arráb. Ex Steud). Ciencia Florestal, Santa Maria, V. 11, n. 2: 93-101

https://doi.org/10.5902/198050981658

Murashige, T., \& Skoog, F. 1962. A revised medium for rapid growth and bioassays with tobacco tissue culture. Physiologia Plantarum, 15, 473-497.

https://doi.org/10.1111/j.1399-3054.1962.tb

Pedroza-Manrique, J. A., González-Molina, S. R., \& Téllez-Ortiz, D. C.2007. Micropropagación de Dodonea viscosa (L) Jacq: una especie en vías de extinción. Revista Colombiana de Biotecnología, 9(2), 33-44.
Pérez-Molphe-Balch E., Ramírez-Malagón R., Núñez-Palenius H. y Ochoa-Alejo N.1999 Introducción al Cultivo de Tejidos

Vegetales. Universidad Autónoma deAguascalientes (ed), Primera edición México. 47:179-183

Rodríguez, $\quad$ M., $\quad$ Matehus,J., Gersti,A.,Santana,M.A.2008 Identificación del agente causal de una bacteriosis en ñame (Dioscorea alata L.) Interciencia 33(7):1-11.

Uribe, M.,E. Delaveaua, C., Garcésa, M., Escobar. R. 200. Efecto de asepsia y fitohormonas en el establecimiento in vitro de Berberidopsis corallina, a partir de segmentos nodales. Bosque 29(1):58-64.

https://doi.org/10.4067/S0717-92002008000

Schendelbek, A. L. 2007. Establecimiento y multiplicación in vitro de Cordia trichotoma V. Tesis de maestría; Universidad Central "Marta Abreu" de Las Villas, Cuba. Universidad Nacional de Misiones, Argentina 
Copyright (c) 2017 Maria de Jesús Martinez Hernández, Sandra Ivonne Sánchez Hernández,

Doris Castillo Rocha y Mauricio Luna Rodriguez

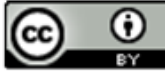

Este tex to está protegido por una licencia licencia Creative Commons 4.0.

Usted es libre para Compartir —copiar y redistribuir el material en cualquier medio o form ato- y Adaptar el documento —remezclar, transformar y crear a partir del material- para cualquier propósito,, incluso para fines comerciales, siempre que cumpla la condición de:

Atribución: Usted debe dar crédito a la obra original de manera adecuada, proporcionar un enlace a la licencia, e indicar si se han realizado cam bios. Puede hacerlo en cualquier form a razonable, pero no de form a tal que sugiera que tiene el apoyo del licenciante o 10 recibe por el uso que hace de la obra.

Resumendelicencia - Textocompletodelalicencia 